Escenas de la recuperación de fábricas en documentales y en ficción: entre la política, el trabajo y la familia

Vanesa Coscia, Marina Moguillansky

Question, Vol. 1, N. 56, e005, octubre-diciembre 2017. ISSN 1669-6581

http://perio.unlp.edu.ar/ojs/index.php/question/article/view/4374

FPyCS | Universidad Nacional de La Plata

La Plata | Buenos Aires | Argentina

Recibido: 22-09-2017 Aceptado: 08-11-2017

Cita sugerida: Coscia, V., y Moguillansky, M. (2017). Escenas de la recuperación de fábricas en documentales y en ficción: entre la política, el trabajo y la familia. Question, 1(56), e005. doi: https://doi.org/10.24215/16696581e005

\title{
Escenas de la recuperación de fábricas en documentales y en ficción: entre la política, el trabajo y la familia
}

\author{
Scenes of recovered factories in documentaries and fiction: between \\ politics, labor and family
}

Vanesa Coscia

Instituto de Investigaciones Gino Germani; Facultad de Ciencias Sociales; Universidad de Buenos Aires/ Consejo Nacional de Investigaciones Científicas y Técnicas (Argentina) vanesa.coscia@gmail.com

\section{Marina Moguillansky} Instituto de Altos Estudios Sociales; Universidad Nacional de San Martín/ Consejo Nacional de Investigaciones Científicas y Técnicas (Argentina) mmoguillansky@gmail.com

\section{Resumen}

Este artículo retoma los debates en torno a los usos de la ficción y el documental en la representación audiovisual del mundo del trabajo y sus conflictos. Para ello, analizamos un 
conjunto de ficciones y documentales que tematizan las recuperaciones de fábricas post 2001 en la Argentina, que comprende a los documentales Mate y Arcilla (Ak Kraak/Alavío, 2003); Fasinpat, fábrica sin patrón (Incalcaterra, 2004); Grissinopoli (Doria, 2004); el largometraje ficcional Industria argentina. La fábrica es para los que trabajan (lacoponi, 2011) y la telenovela La Leona (Lago y Cardozo, 2016). En el análisis comparado de sus estrategias de representación, construimos tres ejes -la política, el trabajo y la familia- que nos permitieron contrastar las potencialidades diferenciales de ficción y documental. Como resultado, destacamos algunos aspectos que la estrategia de la ficción habilita -en contraste con el documental- al mismo tiempo que señalamos los efectos cognoscitivos específicos de este último y que, a pesar de las reflexiones teóricas que insisten en diferenciar ficción y no-ficción, se revelan persistentes.

Palabras clave: fábricas recuperadas; trabajadores; familia; documental; ficción.

\section{Abstract}

This article returns to debates on the uses of fiction and documentary in audiovisual representations of the world of work and its conflicts. To do this, we analyze a corpus of fictions and documentaries that thematize the factories recovered post-2001 in Argentina, including the documentaries Mate y Arcilla (Ak Kraak/Alavío, 2003); Fasinpat (Incalcaterra, 2004); Grissinopoli (Doria, 2004); the fictional feature Industria Argentina. The factory is for those who work (lacoponi, 2011) and the telenovela La Leona (Lake and Cardozo, 2016). In the comparative analysis of their representational strategies, we constructed three axes -politics, work and family- that allowed us to contrast the differential potentialities of fiction and documentary. As a result, we highlight some aspects that the strategy of fiction enables -in contrast to the documentary- while pointing out the specific cognitive effects of the latter and that, despite theoretical reflections that insist on the sameness of fiction and nonfiction, are persistent.

Keywords: recovered factories; workers; family; documentary; fiction.

"Nuestro compromiso debería dirigirse siempre a las áreas de una experiencia hasta ahora silenciosa, fragmentada o francamente mal representada".

Raymond Williams, 1985

En una conferencia de 1985, luego publicada bajo el título "Cine y socialismo", Raymond Williams sostuvo que luego de casi un siglo de cine todavía quedaban áreas de la vida de la 
gente que no se habían considerado. Se refería al mundo del trabajo industrial, sus conflictos y formas de explotación. Pasaron algunas decenas de años más y la afirmación sigue siendo esencialmente cierta, al menos si se la refiere al cine de ficción, ya que las formas cotidianas de opresión y violencia que el capitalismo entraña aún han sido poco y no siempre bien representados por el cine (y el resto de las artes). Diversas hipótesis buscaron explicar la "visibilidad negada" (Medici, 2000) de la explotación industrial, desde la vinculación preferencial del cine con el ocio y el entretenimiento, hasta la imposibilidad de filmar en los espacios de trabajo en general y las fábricas en particular. Según Monterde, "el trabajo se instituye en alteridad del espectáculo" (1997: 12) por el carácter rutinario, cotidiano y trivial de las tareas industriales, que se opondrían así al entretenimiento que busca el cine de ficción, más ligado a lo extraordinario y lo excepcional. El trabajo sólo se tematiza en las ficciones audiovisuales cuando aparecen elementos dramáticos como un accidente o una muerte (Monterde, 1997; Garambois, 2014) (1).

El cine documental, en cambio, tuvo desde los comienzos un marcado interés por el trabajo, que se observa ya en La salida de los obreros de la fábrica (Lumiére, 1895), en los trabajos pioneros de Robert Flaherty y John Grierson, que continúa en documentales contemporáneos. Sin embargo, también para el cine documental, la representación del trabajo industrial ha encontrado límites que precisamente el trabajo de los hermanos Lumière pone sintomáticamente en evidencia. Las cámaras se quedan en la entrada de la fábrica, en el portón, no ingresan al interior: registran la salida, el afuera del trabajo en la fábrica. Tan frecuentes han sido las imágenes de la salida de la fábrica que Harun Farocki las recogió en un documental titulado Workers leaving the Factory (1995). Si bien los directores de cine no podían ingresar a la fábrica, en ella sí entraban las cámaras de los patrones, que produjeron un imaginario parcializado "que le quita algo a lo visible: la fatiga y la pena de los hombres, a veces la violencia inaudita de las condiciones de trabajo" (Monterde, 1997: 10). Un ejemplo es Philip Radio, el documental filmado por Joris Ivens en 1931 por encargo de la propia empresa, un bello filme en el que, no obstante, no podemos dejar de advertir que los trabajadores son representados como piezas de un engranaje industrial. La brutalidad de la explotación, rasgo ineludible del mundo capitalista, no se narra ni se muestra en las películas encargadas por los industriales. Así, la relación entre cine y trabajo no se caracteriza sólo por la falta de imágenes y relatos sino también por su falseamiento.

En este escenario, los ciclos de ocupación de fábricas por parte de los trabajadores abren una oportunidad inédita para los realizadores de entrar a las fábricas y filmar allí, recorrerlas con sus cámaras, registrar el proceso de producción y a los propios trabajadores en sus lugares de trabajo, produciendo otro tipo de relatos e imágenes. En la Argentina, el principal antecedente de ello se produjo en la década de 1960, con las masivas ocupaciones de fábricas en el marco de un plan de lucha de la CGT durante el período de la resistencia peronista. Como señala 
Mariano Mestman (2014), el célebre film-ensayo de Octavio Getino y Pino Solanas conocido como La hora de los hornos, retrata "Las ocupaciones fabriles" en un capítulo de la segunda parte, en el que emplean imágenes de archivo, dramatizaciones con actores y entrevistas a los obreros que participaron en las ocupaciones. El otro antecedente, también dentro del cine político, es la película Los traidores, de Raymundo Gleyzer (1973) que se inicia precisamente con una conversación entre sindicalistas corruptos que se preguntan cómo desactivar la toma de una fábrica, que luego también se pone en escena. Es esta película la que abre una serie de discusiones en su época y continuadas en los años sucesivos acerca de su opción por la ficción, debate que aquí nos proponemos volver a visitar a partir de un conjunto de audiovisuales más o menos recientes.

En la Argentina, la severa crisis económica que eclosionó en 2001 dio lugar a un nuevo proceso de ocupación de fábricas, tomadas por los trabajadores y puestas nuevamente en funcionamiento tras maniobras de vaciamiento y quiebra de los patrones. A su vez, algunas de las experiencias de recuperación de fábricas fueron registradas y narradas en películas documentales, entre las que podemos mencionar Mate y Arcilla; Zanón bajo control obrero (Ak Kraak/Alavío, 2003); Fasinpat, fábrica sin patrón (Incalcaterra, 2004); Grissinopoli (Doria, 2004); No retornable (Cáceres y Parissotto, 2007); De guerreros y maestros (Such y Cufari, 2007); Corazón de fábrica (Molina y Ardito, 2008) y Sin patrón. Una revolución permanente (Colectivo Documental Semillas, 2014).

Dado que uno de los obstáculos para representar el mundo del trabajo era precisamente el control de los dueños sobre sus fábricas, estos procesos ofrecieron una oportunidad única para mostrar desde adentro la experiencia del trabajo obrero e industrial, la relación del hombre con sus máquinas y herramientas, con sus compañeros, las satisfacciones y las frustraciones. Sin embargo, las fábricas recuperadas no reproducen la lógica capitalista sino que exploran la autogestión y la cooperación, resultando así sitios "donde es posible investigar la posibilidad de organizar la vida económica de forma diferente" (Itzigsohn, 2006). De esta manera, como veremos, el mundo del trabajo industrial en el formato capitalista clásico de patrones y obreros continuaría visualmente vedado, porque la fábrica que narran estos documentales es, en definitiva, un nuevo modo autogestionado de trabajo industrial.

En los últimos años, aparecen las primeras ficciones sobre las historias de fábricas recuperadas, con el largometraje Industria argentina. La fábrica es para los que trabajan (lacoponi, 2011), el unitario Fábricas realizado por la productora de contenidos audiovisuales de la Universidad Nacional del Centro (Unicen) y la telenovela La Leona (Lago y Cardozo, 2016). El recurso de la ficción permite abordar visualmente los conflictos que dieron origen a la toma de las fábricas y abre una serie de posibilidades estilísticas y narrativas que, en cierta medida, parecen dramatizar y poner en imágenes los testimonios que los documentales habían recogido. 
En este artículo retornamos al debate en torno a los usos de ficción y documental para la representación del mundo del trabajo y sus conflictos. Específicamente, nuestra indagación se ocupa de contrastar diferentes estrategias representacionales para abordar los procesos de recuperación de fábricas. Partiendo del par tema/motivos (Segre, 1985) estudiamos un corpus audiovisual que comparte un tema -la ocupación de fábricas- y que difiere en cuanto a los motivos que se actualizan, al énfasis y desarrollo que adquiere cada uno de ellos. Adelantamos, como hipótesis, que el modo de representación, ya sea ficcional o documental, incide en las posibilidades y recursos disponibles para abordar ciertos motivos y no otros. De esta manera, nos proponemos indagar las diferentes potencialidades de la ficción y el documental, en tanto estrategias representacionales, a través de una indagación empírica de un corpus audiovisual nucleado en torno de un tema acotado.

En la primera sección del artículo rastreamos algunos antecedentes de la representación de los conflictos del trabajo capitalista en el cine político argentino, considerando las discusiones que mantuvieron los grupos de cineastas militantes en torno de la opción por la ficción hacia la década de 1970. En la segunda sección, presentamos un análisis en contrapunto de los documentales y las ficciones sobre fábricas recuperadas, que se organiza en torno de la constelación de motivos que se asocian con el proceso de toma y recuperación de fábricas. En las conclusiones, retornamos sobre los ejes del debate teórico a partir de los hallazgos de la indagación comparativa y formulamos una serie de interrogantes emergentes.

\section{Cine y mundo del trabajo en la Argentina}

El auge del cine político y militante, hacia las revolucionarias décadas de 1960 y 1970, comienza a revertir la invisibilidad del trabajo y sus conflictos. Las desigualdades, la violencia, los accidentes de trabajo, el maltrato, la explotación empiezan a ser tematizados por algunas producciones documentales y de denuncia. A nivel internacional, para los cineastas comprometidos comienza la discusión sobre cómo representar la lucha de los trabajadores. Hacia fines de la década de 1960, diversos cineastas y grupos de videoactivistas empiezan a filmar conflictos del trabajo y a tematizar la explotación laboral. El Mayo francés y sus ecos en Europa, las luchas estudiantiles y laborales, hacen emerger "un nuevo tipo de cine político y documental, acompañado de la elaboración de teorías del cine" que modelaron la forma en que serían vistos esos filmes (Burton, 2000: 59). La discusión sobre las relaciones entre cine, estética y política problematiza la cuestión del lenguaje cinematográfico. Ya no se tratará sólo de llevar al trabajador a la pantalla para visibilizarlo, sino de poner el foco en "la revelación del conflicto y la explotación de la clase, mediante las convenciones y los códigos indicativos de una forma de arte comercial" (Ibídem: 64). Jean Luc Godard, comprometido con la militancia 
revolucionaria, utilizó la ficción para llegar a un público más amplio que el del cine documental, afirmando además que no era suficiente realizar filmes políticos sino que era necesario hacerlos políticamente, eligiendo la perspectiva del trabajo colectivo y de la radical desestructuración de la forma fílmica (2).

En la Argentina, La Hora de los hornos (Getino y Solanas, 1968) fue un parteaguas para el cine político al plantear de manera provocativa un contrapunto entre la lógica del consumo, el ocio y el espectáculo burgués, por un lado, y la contracara de la violencia de la explotación de los trabajadores, por el otro. Esta película-acción que dio nacimiento al Grupo Cine Liberación buscó generar conciencia política entre los espectadores, recogiendo las experiencias de resistencia y luchas obreras en una reflexión sobre la dependencia y el imperialismo. Entre los grupos de cine político y militante de la época, Cine de la Base, nucleado en torno a la figura de Raymundo Gleyzer, concedió una atención privilegiada al mundo del trabajo, a la dinámica sindical y a la explotación capitalista. En ese sentido, Los traidores (Raymundo Gleyzer, 1973), se convirtió en unos de los filmes más debatidos de la época -y aún mucho tiempo despuéstanto por la tematización inédita de la burocracia sindical argentina, como por la elección de la ficción para llegar a un público más amplio. Al respecto, Álvaro Melián sostiene que originalmente pensaban hacer un documental pero se dieron cuenta de que el material de la burocracia al que podían acceder no era suficiente para penetrar en la lógica de funcionamiento más allá de su retórica.

\footnotetext{
Entonces empezamos a orientarnos por el terreno de la ficción, que era dónde íbamos a encontrar más posibilidades (...) porque ya se empezaba a percibir que el tema del documental tenía sus límites, los del discurso prefijado, del material para convencidos, en fin...para nosotros, un trabajo sobre la burocracia sindical exigía producir algo que significara abrir un debate. (...). Nos molestaba el hecho de que el cine argentino no hubiera atendido la realidad (Peña y Vallina, 2000: 94).
}

A los fines de nuestra indagación, interesa analizar las potencialidades de la ficción para representar el trabajo fabril al eludir las restricciones impuestas por los dueños de los establecimientos. Es interesante observar que, como indica Mestman, la estrategia ficcional hubiera permitido crear escenas al interior de la fábrica, sin embargo Gleyzer decide "presentar las partes en conflicto (bases-burocracia) con un significante visual muy extendido en esos años: los obreros tras el alambrado de la fábrica", imágenes registradas desde afuera de la fábrica que han sido bastante extendidas en las producciones de tipo documental sobre los conflictos laborales, no sólo a nivel nacional (Mestman, 2008: 11). También es relevante recordar que en su época, tanto LosTraidores (1973) como ciertos filmes realizados por el grupo Cine Liberación (La hora de los hornos, 1968; El camino hacia la muerte del viejo Reales, 1971 y Los hijos de Fierro, 1975) otorgaron un lugar privilegiado a las ocupaciones 
fabriles (3). A nivel internacional, entre 1968 y 1973, aparecen muchos filmes militantes en torno a las ocupaciones de fábricas (4).

Sin embargo en la Argentina el cine político y social fue abruptamente cortado por la dictadura cívico-militar de 1976-1983 que llevó adelante la censura, la persecución y el asesinato de cineastas revolucionarios. Desde la recuperación democrática, el retorno del cine político tuvo dos grandes vertientes: una volcada a la recuperación de la memoria y otra centrada en la visibilización de la exclusión social (Lusnich, 2009). Dentro de esta segunda vertiente se inscriben los documentales políticos que vuelven a tomar vuelo en torno de la crisis socioeconómica que atraviesa la Argentina hacia 2001. Una de las líneas temáticas de interés fueron los procesos de ocupación de fábricas.

Los documentales sobre fábricas ocupadas se dieron la tarea de registrar la situación de los trabajadores y de las fábricas ocupadas, acompañando en algunas ocasiones las asambleas y los momentos más álgidos de lucha. De esta manera, favorecieron la difusión de los conflictos y de la perspectiva de los trabajadores, contribuyendo así a legitimar estas ocupaciones ante la opinión pública, si bien sus circuitos de exhibición se caracterizaron por ser fundamentalmente otros espacios ocupados, de lucha y/o de militancia tanto nacionales como internacionales. En muchos casos, resultaron claves las alianzas que se fueron tejiendo entre los movimientos de trabajadores, ciertos espacios de activismo transnacional y fondos internacionales, que otorgaron financiamiento para realizar las filmaciones. Así, es frecuente encontrar realizadores extranjeros (italianos, alemanes, canadienses) militantes, activistas y/o comprometidos con la realidad social argentina, a la cabeza de algunas de las producciones más relevantes (Coscia, y Moguillansky, 2016).

La producción audiovisual sobre las fábricas recuperadas fue en un primer período exclusivamente documental (2004-2010). Pero luego empezaron a aparecer también ficciones que construyeron sus tramas argumentales en torno de las fábricas ocupadas y de sus trabajadores. Entre ellas se destacan el largometraje Industria Argentina, la fábrica es para quienes trabajan (Ricardo Díaz lacoponi, 2011), la telenovela La Leona (Pablo Lago y Susana Cardozo, 2015) con 116 capítulos que se emitieron en la televisión de aire y el unitario Fábricas (2015) de ocho episodios, emitido por la televisión pública. Estas ficciones colocaron la temática del trabajo colectivo, autogestionado y cooperativo en el centro de las narraciones. La estrategia de la ficción, que adquiere características diferenciales según se trate de cine o televisión, habilita posibilidades nuevas para mostrar y problematizar los conflictos del mundo del trabajo, al permitir narrar desde adentro y desde la intimidad de la vida cotidiana el proceso de vaciamiento, quiebra, ocupación y recuperación de una fábrica. En la siguiente sección, nos dedicamos a analizar en forma comparada el tratamiento de la recuperación de fábricas por parte de documentales y ficciones audiovisuales. 


\section{Representar las fábricas recuperadas. Ficciones y documentales}

Las discusiones teóricas acerca de las fronteras entre ficción y documental han formulado una serie de hipótesis para establecer sus rasgos diferenciales. La propuesta de Bill Nichols (1997) sostiene que la ficción presenta una historia que transcurre en un mundo imaginario, mientras que el documental propone un argumento sobre el mundo histórico e involucra cierta misión de transformarlo. Para Plantinga, lo esencial de la no-ficción es que construye una "reproducción verídica aseverada" (2005: 114) en la cual el realizador se compromete a mostrar algo real sobre el mundo y el espectador confía en la veracidad de lo que está viendo. Así, "no es la forma del discurso lo que distingue a la no ficción de la ficción, sino la postura tomada ante el mundo que proyecta" (Platinga, 2014: 123). En este sentido, la distinción entre ficción y documental remitiría al contrato de lectura y no a diferencias textuales. Sin embargo, incluso esta demarcación pragmática se ve tensionada por los falsos documentales, los documentales poéticos o los films-ensayo. En la zona fílmica que aquí nos interesa, el cine político, algunos de los filmes más interesantes han procurado intencionalmente cruzar las fronteras entre ficción y documental, como La hora de los hornos (Solanas y Getino, 1969) y Los traidores (Gleyzer, 1974).

Sin embargo, en el corpus que aquí trabajamos, la diferenciación de documentales y ficciones es clara. Por ello mismo, los materiales nos permiten aproximarnos a una distinción empírica acerca de las potencialidades de cada estrategia para representar determinados eventos. La comparación parte de la consideración del contrapunto entre documentales y ficciones construido con las categorías de tema/motivo de Segre (1985) que nos permiten, partiendo del núcleo común de las fábricas recuperadas, analizar los modos en que los motivos se actualizan con diferentes recursos y énfasis. A los fines expositivos, construimos tres ejes analíticos a partir de los cuales desarrollar la comparación: la política, el trabajo y la familia.

\section{Política, sindicatos y traiciones}

La fábrica recuperada que más atención suscitó entre los documentalistas ha sido sin dudas Zanón, la productora de cerámicas más importante de América Latina. Uno de los primeros documentales que retrató el caso fue Mate y Arcilla. Zanón bajo control obrero realizado por videoactivistas del grupo Ak Kraak (Alemania), en colaboración con el Grupo Alavío. Los trabajadores que se organizaron para resistir a la quiebra de las fábricas tuvieron que lidiar en ocasiones con sindicalistas que sostenían posiciones negociadoras hacia la patronal e incluso facilitaban los despidos (Calloway, 2013). 
El caso de Zanón, la fábrica ceramista localizada en Neuquén, es paradigmático al respecto, como muestra extensamente el documental No retornable (Cáceres y Parisotto, 2007): los trabajadores tuvieron que, en primer lugar, recuperar el control del sindicato ceramista, lo cual les permitió llevar adelante acciones de protesta frente a los intentos de vaciamiento del patrón, y finalmente fue el espacio desde el cual se organizaron para tomar la fábrica. En estos relatos, los trabajadores tienen una identidad política -uno de ellos, Raúl Godoy, se reconoce como militante del Partido de los Trabajadores Socialistas (PTS)-; la organización sindical se representa como central y las relaciones con otros actores sociales son jerarquizadas. El rol de la justicia, del gobierno, de la comunidad local son tematizados como relevantes para comprender el proceso de recuperación de la fábrica.

En cambio, en las ficciones analizadas, el proceso de lucha y la recuperación de la fábrica se representan como asunto exclusivo de los trabajadores, que se mantienen al margen de la política. En Industria Argentina no hay referencia alguna al movimiento obrero argentino ni a la vinculación de los trabajadores con tendencias político-partidarias o a las experiencias sindicales, de militancia o de activismo previas. Se resalta la necesidad de unidad de los trabajadores para llevar adelante la lucha colectiva de recuperación de la fábrica. En La Leona, si bien aparece tematizado el rol del sindicato, este también se representa de modo aplanado, debido a cierta tipificación del "sindicalista" que no da cuenta de las complejidades de la dinámica sindical, ni de identidades políticas o de una historia concreta en el movimiento obrero. El personaje de Coco, delegado sindical de los trabajadores en la fábrica textil, se construye como un traidor. A cambio de dinero, traiciona a los trabajadores más de una vez. De este modo, no se privilegia en estas ficciones un marco de interpretación política de los acontecimientos y cuando se lo hace se vincula la política con un lugar "sucio", de corrupción. Dicha representación tiende a esquematizar la relación entre la política, los trabajadores y los sindicatos, universalizando y simplificando estos vínculos (5).

En esta relación entre política y corrupción, la noción de traición aparece como central en las producciones audiovisuales de ficción analizadas (6). En La Leona, a través del personaje de Coco como delegado sindical que traiciona a sus compañeros trabajadores; pero también a través del personaje de Eugenia que se avergüenza y rechaza su lugar humilde y de clase trabajadora, y estando en el área administrativa de la empresa con la gerencia de recursos humanos es una de las encargadas de ofrecer los retiros voluntarios de miseria que otorga la fábrica para reducir el personal. En Industria Argentina uno de los trabajadores traiciona a sus compañeros aliándose con el patrón, a quien le proporciona información y a quien favorece al desalentar los paros y la toma de la fábrica.

En cambio, en los documentales el traidor casi no es tematizado y en todo caso no se logra su visualización o figuración; los relatos de los trabajadores, eventualmente, señalan una traición general de parte de los sindicatos, sin identificar personajes singulares. Sin embargo, puede 
aparecer el patrón (nombrado por los trabajadores, mostrado en entrevistas o bien a partir de imágenes de archivo) presentado como la figura del enemigo que, en cierta forma, traiciona la confianza de los trabajadores. En este tipo de producciones, se destaca la vinculación con la historia política del país (contra los militares y la lucha por los derechos humanos que se muestra en Fasinpat), con las luchas del movimiento obrero, o con los líderes políticos y sindicales como la recurrente aparición de Raúl Godoy, como parte del nuevo sindicato antiburocrático de la fábrica y como miembro de un partido de izquierda. En estos casos, la política no sólo no parece "ensuciar" sino que parece ser clave y motorizadora de los cambios que permiten la lucha y la organización de los trabajadores: ocupar la fábrica, recuperarla, poner en marcha un proceso de autogestión, luchar por su expropiación, defenderse de los desalojos.

Tanto ficciones como documentales comparten la idealización de la lucha, del rol de los trabajadores y de la fábrica recuperada a través de la autogestión laboral. Ni la ficción ni el documental resaltan o destacan las contradicciones y los conflictos que surgen luego, al llevar adelante el proceso de trabajo en la fábrica recuperada, gestionada por sus propios trabajadores. Como destaca el historiador Pablo Hudson (2011), el funcionamiento de las empresas recuperadas tras un cierto tiempo -y en la medida de su propio éxito- coloca a los trabajadores en el rol de patrones, y la lógica del capitalismo los lleva, en ocasiones, a reproducir el modelo de explotación que conocieron previamente. En otros casos, las fábricas recuperadas se han enfrentado a severas restricciones operativas, a dificultades legales por la posesión del inmueble, a conflictos internos entre los trabajadores, sobre lo cual se puede consultar el trabajo de Dicapua, Mascheroni y Perbellini (2015). Estos problemas son escasamente tematizados por los audiovisuales, y en todo caso, aparecen como problemas temporarios que se superan con facilidad. De esta manera, todos los audiovisuales analizados arriban a un final feliz y esperanzador, que alude al cambio social y a un futuro de mayor justicia social, libertad e igualdad.

\section{Trabajadores y procesos de trabajo en la fábrica}

Los documentales dedican un tiempo extenso al registro de los procesos de trabajo con planos detalle que van mostrando la secuencia de la producción, las máquinas y herramientas, siempre con una cierta centralidad para los propios operarios.

El documental más interesante a nivel visual en cuanto a la representación del trabajo es $D e$ guerreros y maestros (Such, 2008). Este filme surge del interés de una artista plástica (Marta Such) por el proceso de Zanón-Fasinpat, que la lleva a pintar una serie de cuadros, en colaboración con otros artistas, en los que retratan el trabajo de la fábrica. Este documental recorre todas las instalaciones y reconstruye visualmente la totalidad del proceso de 
producción, así como las tareas de apoyo que se realizan en la fábrica. Se presta atención a todo tipo de tareas: preparación del material, traslado, resguardo, producción de las piezas, control de calidad, limpieza, empaquetado, seguridad. A través de los diálogos que la artista sostiene con los trabajadores, aprende a nombrar cada una de esas máquinas y herramientas, los puestos de trabajo y los materiales que se utilizan, al tiempo que dota al documental de un contrato de lectura cómplice y pedagógico que construye con el espectador. La artista pinta los camiones, la playa, los molinos, las palas mecánicas, la prensa, la arcilla en montones y en sus distintos estadios de elaboración (la pasta, el bizcocho, el cerámico). Los cuadros que se van mostrando en el filme proponen una figuración plástica de los trabajadores realizando sus tareas, con sus rostros visibles y personalizados, entrelazados con el espacio de trabajo -para lo cual recurre al fundido- con la intención de mostrar una cierta simbiosis del trabajador y los medios de producción, una desalienación y una identificación entre los instrumentos y los trabajadores con destrezas técnicas.

Los otros documentales también ofrecen representaciones audiovisuales del proceso de trabajo. En todos se incluyen planos detalle de las herramientas y de las máquinas en producción, que suelen ser acompañadas con música instrumental -que combina sonidos mecánicos producidos por las maquinarias industriales- produciendo así cierta estetización del mundo fabril. Esta figuración un tanto idealizada de los procesos de producción, del mundo del trabajo y de la fábrica vistos desde su interior, contrasta con la invisibilidad del trabajo y con su representación desde los bordes exteriores que ya señalamos como típica de buena parte del cine del siglo XX.

Las ficciones se detienen menos en la figuración del trabajo. En La Leona, el espacio de la fábrica es el contexto en el que se desarrollan vínculos de amistad, relaciones amorosas e infidelidades, donde se traman encuentros y festejos, aunque también se organizan asambleas, se negocia con los patrones y se va construyendo la historia de la cooperativa. Las tareas específicas del trabajo se muestran poco, en comparación con lo que ocurre en los documentales. En Industria Argentina. La fábrica es para quienes trabajan ocurre algo similar: las escenas de producción son muy escasas y ni siquiera resulta del todo claro a qué se dedica la fábrica.

\section{Escenas de la intimidad: la familia y la vida cotidiana}

La crisis de una fábrica es también la crisis de sus trabajadores, que sufren demoras en el cobro de sus salarios, el deterioro de las máquinas y las herramientas, la reducción de la jornada de trabajo y el miedo a ser despedidos. La ocupación de la fábrica también supone un período más o menos prolongado de incertidumbre, ausencia de ingresos, largas jornadas de presencia física en el establecimiento e incluso luchas y enfrentamientos con las fuerzas 
policiales que ponen en riesgo la vida de los trabajadores. Las familias de los trabajadores se ven duramente afectadas en este proceso. El barrio, que muchas veces funciona en torno de las fábricas cuando su dimensión es importante, también sufre las consecuencias. Ahora bien, ¿cómo se reconstruye este aspecto de la ocupación de fábricas en los audiovisuales, y qué matices diferenciales proponen la ficción y el documental?

Tanto Industria Argentina como La Leona reconstruyen el mundo familiar y la vida cotidiana de los trabajadores, sus recorridos por el barrio y las redes de sociabilidad en las que se encuentran inmersos. La necesaria síntesis que supone la menor duración del largometraje con respecto a la telenovela tiene su correlato en un menor desarrollo de los personajes y de los conflictos familiares, que en La Leona adquieren una mayor densidad. Sin embargo, en Industria, considerando la economía narrativa del filme, la situación de Juan y el conflicto con su esposa, que desea que abandone la lucha de la fábrica y busque un trabajo "normal", ocupan un lugar muy relevante. En esta película, el protagonista y su familia forman un núcleo narrativo que tensiona la decisión de sostener la toma de la fábrica. La esposa de Juan presiona para que acepte un nuevo trabajo en un vivero que le ofrece un familiar, y si bien Juan se resiste durante un tiempo, ante la insistencia de su mujer embarazada, decide alejarse de sus compañeros y tomar esa nueva oportunidad. Pero se trata de un trabajo en otro rubro, con el que no se siente identificado y para el cual no está preparado. Una escena lo muestra irritado con un cliente que le solicita más información al respecto del pasto que ha comprado, dado que no puede responderle. Esa situación límite y la conciencia de que sus compañeros lo necesitan llevarán a que Juan decida finalmente retornar a la fábrica, y lo hará en el clímax del conflicto, como una suerte de "salvador".

La presencia del entramado familiar como factor de presión o de apoyo para los trabajadores complejiza el relato que permite construir la ficción como estrategia representacional, ya que este aspecto al aparecer en los documentales sólo referido por las voces y reflexiones de los protagonistas parece perder cierta potencia. Al contrario de esta potencialidad que permite la ficción, en los documentales los familiares aparecen principalmente a través de comentarios 0 relatos de trabajadores (que cuentan las dificultades para dejar a la familia, en otros casos se refieren al apoyo) y excepcionalmente en alguna escena en que los realizadores entrevistan a la familia (en La toma, de Klein).

\section{Conclusiones}

Los vínculos entre el cine y el mundo del trabajo han sido sinuosos. Históricamente el cine ficcional se ocupó poco de tematizar los conflictos y la opresión del capitalismo, y si bien el cine documental se interesó en ello, quedó sin embargo limitado a observar desde los portones de 
las fábricas. Los procesos de ocupación fabril y producción bajo control obrero abren el mundo industrial a la mirada cinematográfica, precisamente en el punto histórico en el que la explotación capitalista muta hacia nuevas formas de organización de la producción. En cierto sentido, nos encontramos aquí nuevamente con la belleza de lo muerto -la fórmula propuesta por Michel De Certeau (1999) con respecto a la cultura popular- con un proceso en el cual cierta formación debe "perderse" antes de poder ser cabalmente captada. Más aún, porque el propio gesto de captación cinematográfica transforma el objeto, la mirada cinematográfica modifica la percepción del trabajo al estetizarlo. La reflexión de Walter Benjamin señala que los espacios de la fábrica eran "horribles, incomprensibles, y desesperadamente tristes. O más bien, lo eran y lo parecían, antes del advenimiento del cine" (1927). El cine tiene una eficacia prismática -según Benjamin- que transforma a esos espacios del ambiente cotidiano y los torna comprensibles, significativos y apasionantes.

En esta investigación, rastreamos los modos en que diversos aspectos de la ocupación de fábricas fueron retratados con diferentes énfasis en las producciones audiovisuales documentales y ficcionales analizadas. En algunos casos, encontramos que las ficciones ponen en escena y dramatizan los relatos que, en los documentales, aparecían a través de testimonios y entrevistas. Así es que se expande, en las ficciones, la representación del mundo familiar y de la vida privada de los trabajadores, para incorporar narrativamente las consecuencias de la toma de la fábrica en sus entornos cotidianos. Pero no es sólo en el terreno de la trama cotidiana y familiar que se desarrollan las ficciones, sino que también encontramos un proceso similar en la tematización de otros aspectos de la ocupación de fábricas. Lo que sólo aparecía sugerido en los documentales (la figura de los patrones, las traiciones sindicales, la apatía de una porción de los trabajadores) es ampliamente representado en las ficciones y sobre todo, es concretizado y puesto en imágenes aquello que sólo podía "contarse" verbalmente a través del relato de los trabajadores entrevistados.

Pero si las ficciones muestran potencialidades para abrir el mundo de la vida cotidiana y explorar ciertos aspectos de los procesos de recuperación de fábricas, también presentan límites. El corpus de ficciones aquí analizado aplana la densidad histórico-política de los procesos de ocupación fabril: no hay en ellas movimiento obrero organizado, ni identidades políticas o trayectorias que permitan reconocer la historicidad y la politicidad del entramado en el que se inserta la fábrica. Sin embargo, el antecedente de Los traidores, de Gleyzer, que es una ficción y no padece de este tipo de problemas, indica una cautela a la hora de conectar este tipo de dificultades con la estrategia de la ficción. Quizás otras ficciones logren resolver de maneras más efectivas la representación de este tipo de historias.

Por último, más allá de las notorias diferencias, señalamos un aspecto que recorre a todas las producciones, documentales y ficcionales, sobre las fábricas recuperadas. Nos referimos aquí a la dificultad para representar los conflictos que se producen en el funcionamiento de las 
fábricas bajo control obrero, que tienden a dejarse de lado bajo la presunción de un final feliz idealizado.

\section{Notas}

(1) No obstante, algunas películas puntuales se ocuparon del trabajo, como la alemana La tragedia en la mina (1931); la francesa El delito del señor Lange (1935) o la estadounidense Tiempos Modernos (1936). Como señala Monterde (2012), ciertos períodos históricos han tenido una sensibilidad mayor y una preocupación por tematizar el trabajo, como el neorrealismo italiano con Ladrones de Bicicletas (1948) y La Tierra Tiembla (1948) entre otras, o los cineastas que hacia fines de la década de 1960 se preocupan por el mundo industrial y las luchas de los trabajadores (Chris Marker y Jean-Luc Godard, entre otros). Para ampliar sobre el cine europeo y la influencia del neorrealismo italiano en otros contextos revisar Burton (2000).

(2) Para ampliar sobre la trayectoria de Godard puede consultarse a Sorlín (2011). En el mismo período, las películas de Ken Loach en Inglaterra, I compagni (1963) de Monicelli en Italia o Todo va bien (1972) de Godard y Gorin en Francia son quizás los ejemplos europeos de cine de ficción más significativos en relación con la representación de las condiciones de trabajo, derechos de los trabajadores, desocupación y explotación, aunque hay otros posibles a tener en cuenta.

(3) En La Hora de los Hornos, entre los conflictos por ocupaciones de fábricas que se muestran, interesa destacar aquí la ocupación de la textil La Bernalesa, en Quilmes, "ilustrada con imágenes de obreras detrás de las rejas y de la fábrica en pleno funcionamiento", es decir, con la continuidad de la producción bajo control de las trabajadoras (Mestman, 2011: 124). Sin embargo, la mayoría de los filmes no resaltan la ocupación de la fábrica para el control obrero sino más bien como método para reforzar el poder de negociación de los sindicatos en relación con el empresariado o con el Estado.

(4) La mayor parte focaliza en la ocupación de la fábrica como una fase superior de la huelga y la lucha obrera, y no como la ocupación del espacio laboral bajo gestión de los trabajadores. En los años siguientes, como excepción y si bien inspirada en parte en Apollon: una fábrica ocupada (Gregoretti, 1969), el filme español Numax presenta (Jordá, 1979) narra la lucha de los trabajadores de una industria de electrodomésticos en Barcelona, reconstruyendo la ocupación de más de un año, durante el cual los trabajadores mantuvieron la producción y la gestión de la empresa (Monterde, 1997).

(5) Durante los procesos de ocupación y recuperación de fábricas pos 2001, tal como se analizó en un trabajo previo, no en todos los casos la vinculación del sindicalismo con estos procesos ha sido de indiferencia o de obstaculización. La complejidad y los matices de los diferentes casos se relaciona con fábricas que ya tenían una comisión interna y un proceso previo de organización, la presencia de delegados en los lugares de trabajo, los conflictos entre seccionales "rebeldes" y conducción nacional etcétera (Coscia y Perbellini, 2014).

(6) La idea de traición tiene una larga genealogía en el cine argentino (con un antecedente central precisamente en la ya mencionada Los traidores) y más allá del cine, también es una figura nuclear de ciertas series literarias, ensayísticas y de la cultura política argentina en general. Puede verse al respecto, entre otras referencias, el trabajo de Ana Longoni (2007).

\section{Bibliografía}


Coscia, V. y Moguillansky, M. (2016). Militantes Kino und transnationaler Aktivismus in Dokumentationen über übernommene Fabriken in Argentinien. Peripherie, 36, pp. 455480 .

Coscia, V. y Perbellini, M. (2014). Ocupación y recuperación/reconversión de fábricas en Argentina y en Italia: los modos de actuar de los sindicatos en contextos de crisis laboral. Revista Multidisciplinar Vozes dos Vales, III(6). Universidade Federal dos Vales do Jequitinhonha e Mucuri (UFVJM), Minas Gerais, Brasil.

Benjamin, W. (2009). La situación del arte cinematográfico en Rusia. En Obras (libro II, vol. 2). Madrid: Abada.

Burton, A. (2000). Filmare cose diverse o filmare in maniera diversa. Lavoro e lavoratori nel cinema europeo del dopoguerra. En Medici, A. (ed.). Filmare il lavoro (pp. 52-68). Roma: AAMOD.

Calloway, C. (2013). Fábricas y empresas recuperadas: el devenir de las tensiones con los sindicatos y los movimientos que las nuclean. V Congreso Internacional de Investigación y Práctica Profesional en Psicología, UBA. Recuperado de http://www.aacademica.org/000-054/558. Acceso 06/07/2017.

Como, E. (2000). Paessagi di fabbrica. Ciminiere e stabilmenti industriali nel cinema italiano dal fordismo al postfordismo. En Medici, A. (ed.). Filmare il lavoro (pp. 118-129). Roma: AAMOD.

De Certeau, M. (1999). La cultura en plural. Buenos Aires: Nueva Visión.

Dicapua, M.; Mascheroni, J.; Perbellini, M. (comps.). (2015). Problemáticas legales, sociales y subjetivas de las y los socios de las cooperativas de trabajo. Reflexiones integradas desde la formación académica, la práctica investigativa y las experiencias de extensión. Rosario: Ediciones DelRevés.

Garambois, S. (2014). II lavoro in Tv. II grande assente dell'informazione. En Gallozi, G. (ed.). II lavoro o la vita. Cinema, salute, ambiente. Annali dell'Archivio Audiovisivo del Movimento Operaio e Democratico (pp.117-126). Grosseto: Effigi.

Hudson, J. P. (2011). Acá no, Acá no me manda Nadie. Empresas Recuperadas por Obreros 2000-2010. Buenos Aires: Tinta y Limón.

Itzigsohn, J. (2009). La gestión democrática del trabajo. Observatorio Social sobre Empresas Recuperadas Autogestionadas, IIGG-FCS-UBA, Recuperado de http://webiigg.sociales.uba.ar/empresasrecuperadas/PDF/ltzigsohnEEUU.pdf Acceso 01-06-2017

Longoni, A. (2007). Traiciones. La figura del traidor en los relatos acerca de los sobrevivientes de la represión. Buenos Aires: Grupo Norma. 
Lusnich, A. L. (2009). El cine político y social en la Argentina entre 1969 y la actualidad. En Lusnich, A. L. y Piedras P. (eds). Una historia del cine político y social en Argentina (1969-2009) (pp 23-43). Buenos Aires: Nueva Libreria.

Medici, A. (2000). Una ricerca in progress. En Medici, A. (ed.). Filmare il lavoro (pp.9-23). Roma: AAMOD.

Medici, A. (2017). II cinema saggistico di Ansano Giannarelli. Torino: Lindau.

Mestman, M. (2008). Mundo del trabajo, representación gremial e identidad obrera en Los traidores (1973). En Nuevo Mundo Mundos Nuevos. Recuperado de https://nuevomundo.revues.org/44963

Mestman, M. (2011). Immagine dell'Autunno caldo argentino. Battagle (anche visive) della protesta operaia. En Casula, C. F.; Medici, A.; Olivier, C. y Scarnati, P. (Eds.). Ciak si Iotta. Il cinema dell'Autunno caldo in Italia e nel mondo (pp. 115-127). Roma: Liberetá.

Mestman, M. (2014). Opciones visuales en torno a la protesta obrera. En Archivos de historia del movimiento obrero y la izquierda, 4 (pp. 11-30). Buenos Aires: Adhilac-Asociación de Historiadores Latinoamericanos y del Caribe.

Monterde, J. E. (1997). La imagen negada. Representaciones de la clase trabajadora en el cine. Valencia: Filmoteca Generalitat Valenciana y Festival de Cine de Gijon.

Nichols, B. (1997). La representación de la realidad. Cuestiones y conceptos sobre el documental. Barcelona: Paidós

Peña, F. M. y Vallina, C. (2000). El cine quema: Raymundo Gleyzer. Buenos Aires: Ed. de la Flor.

Plantinga, C. (2014). Retórica y representación en el cine de no ficción. México: UNAM.

Plantinga, C. (2005). What a Documentary Is, After All. The Journal of Aesthetics and Art Criticism, 63, pp. 105-117.

Segre, C. (1985). Principios de análisis del texto literario. Barcelona: Ed. Crítica.

Sorlín, P. (2011). II lavoro, la storia, la memoria: cinétracts e cinema militante francese dal 1968 e del 1969" En Casula, C. F.; Medici, A.; Olivier, C. y Scarnati, P. (Eds.). Ciak si lotta. II cinema dell'Autunno caldo in Italia e nel mondo (pp. 129-136). Roma: Libertá. 